\title{
Two novel azaspiracids from Azadinium poporum, and a comprehensive compilation of azaspiracids produced by Amphidomataceae, (Dinophyceae)
}

\author{
Bernd Krock $^{\mathrm{a}, *}$, Urban Tillmann ${ }^{\mathrm{a}}$, Jan Tebben ${ }^{\mathrm{a}}$, Nicole Trefault ${ }^{\mathrm{b}}$, Haifeng $\mathrm{Gu}^{\mathrm{c}}$ \\ ${ }^{a}$ Alfred Wegener Institut-Helmholtz Zentrum für Polar- und Meeresforschung, Am Handelshafen 12, 27570 Bremerhaven, Germany \\ ${ }^{\mathrm{b}}$ GEMA Center for Genomics, Ecology \& Environment, Faculty of Sciences, Universidad Mayor, Camino La Pirámide 5750, Huechuraba, Santiago, Chile \\ ${ }^{\mathrm{c}}$ Third Institute of Oceanography, State Oceanic Administration, Xiamen 361005, China
}

\section{A R T I C L E I N F O}

\section{Keywords:}

Toxic dinoflagellates

Azadinium

Amphidoma

Azaspiracid shellfish poisoning (AZP)

LC-MS/MS

CID spectrum

\begin{abstract}
A B S T R A C T
Two novel azaspiracids (AZA) with a molecular mass of $869 \mathrm{Da}$ were found in Pacific strains of Azadinium poporum and characterized by tandem mass spectrometry and high resolution mass spectrometry (HRMS). One compound, AZA-42, was found in Az. poporum strains AZFC25 and AZFC26, both isolated from the South China Sea. AZA-42 belongs to the 360-type AZA that in comparison to AZA-1 has an additional double bond in the F-I ring system of AZA comprising C28-C40. The other compound, AZA-62, was detected in Az. poporum strain 1D5 isolated off Chañaral, Northern Chile. Mass spectral data indicate that AZA-62 is a variant of AZA-11 with an additional double bond in the C1-C9 region of AZA. In addition to the description of the two novel AZA, a comprehensive list of all AZA known to be produced by species of the genera Azadinium and Amphidoma comprising 26 AZA variants is presented.
\end{abstract}

\section{Introduction}

Azaspiracids (AZA) belong to the most recently identified group of phycotoxins. They became evident in 1995 when consumers of Irish mussels showed symptoms of diarrheic shellfish poisoning (DSP) in the Netherlands (McMahon and Silke, 1996) despite the absence of DSP toxins in the shellfish. The causative compound was identified three years later as a polyether toxin with cyclic amine (aza group), a trispiro-group and a carboxylic acid group and was therefore named AZASPIR-ACID-1 (AZA-1, Satake et al., 1998). In the following years, several analogs of the toxin were isolated from contaminated shellfish and structurally elucidated (Ofuji et al., 1999, 2001; James et al., 2003). Shortly thereafter, more than two dozen shellfish metabolites of AZA-1 and AZA-2 were reported by Rehmann et al. (2008). Despite the rapid increase of knowledge about structural variants of AZA, the AZA-producing organisms remained unknown. During an oceanographic expedition in the North Sea in 2007 the small dinoflagellate Azadinium spinosum was unambiguously identified as a source of AZA-1 and AZA-2 (Krock et al., 2009). In the following years other species of the family Amphidomataceae were reported to be producers of AZA (Krock et al., 2012; Percopo et al., 2013) and novel AZA variants were detected increasingly (Krock et al., 2012; Kilcoyne et al., 2014; Krock et al., 2014, 2015; Kim et al., 2017; Rossi et al., 2017). In addition to novel AZA produced de novo by Amphidomataceae, also new shellfish metabolites of AZA-1 and AZA-2 were described (Kilcoyne et al., 2018). So far, the structures of AZA-1 to $-6,-26,-33,-34,-36$ and -37 have been verified by NMR techniques (Satake et al., 1998; Ofuji et al., 1999, 2001, Kilcoyne et al., 2012, 2014; Krock et al., 2015; Kilcoyne et al., 2018) while the structure analogs of all other AZA have been inferred from MS/MS fragmentation patterns and chemical derivatization.

By general convention, AZA are numbered chronologically depended on their time of discovery, which results in a mixture of AZA produced by dinoflagellates and shellfish metabolites. The aim of this study is to give a comprehensive overview of all currently known AZA produced by dinoflagellates and their global distribution. In addition, two novel AZA found after thorough analysis by tandem mass spectrometry and high resolution mass spectrometry in Azadinium poporum strains from the Northwest and the Southeast Pacific are reported.

\section{Materials and methods}

\subsection{Origin, culture conditions and harvest of strains}

The Azadinium poporum strains AZFC25 and AZFC26 were isolated from Fangchenggang, South China Sea $\left(21^{\circ} 29^{\prime} 58.20^{\prime \prime} \mathrm{N}, 108^{\circ} 13^{\prime}\right.$ 53.20" E) in April 2011 (Fig. 1). Cultures of Az. poporum were grown in $200 \mathrm{~mL}$ Erlenmeyer flasks at $20^{\circ} \mathrm{C}, 90 \mu \mathrm{mol}$ quanta $\mathrm{m}^{-2} \cdot \mathrm{s}^{-1}$ under a 12:12 h light: dark cycle. At exponential phase about $10^{7}$ cells were

\footnotetext{
* Corresponding author.

E-mail address: bernd.krock@awi.de (B. Krock).
} 


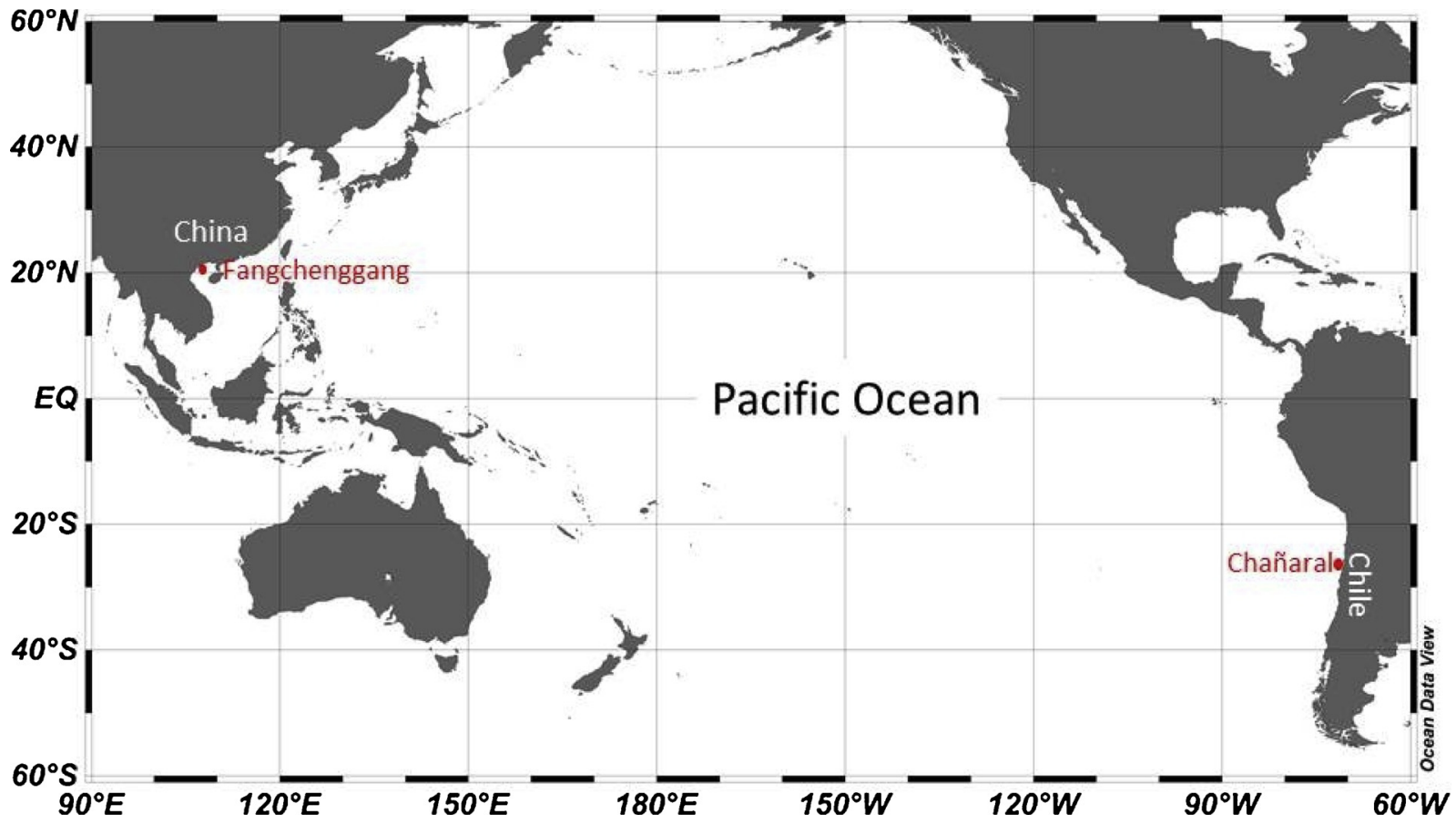

Fig. 1. Map showing the locations where A. poporum strains AZFC25 and AZFC26 (Fengchenggang) and 1D5 (Chañaral) were isolated.

collected by centrifugation. Exponential phase was determined via linear regression of log-transformed cell count time series.

Strain 1D5 was isolated near Chañaral, Northern Chile $\left(26^{\circ} 08^{\prime} 26.0^{\prime \prime}\right.$ S, $70^{\circ} 41^{\prime} 15.2^{\prime \prime} \mathrm{W}$; Fig. 1) and grown and harvested as detailed in Tillmann et al. (2017b).

\section{2. $L C-M S / M S$ measurements}

Selected reaction monitoring (SRM) measurements were performed as detailed in Kim et al. (2017) on a triple quadrupole mass spectrometer (API 4000 QTrap, Sciex, Darmstadt, Germany) equipped with a Turbo lon Spray interface, coupled to a liquid chromatograph, (model 1100, Agilent, Waldbronn, Germany). The liquid chromatograph included a solvent reservoir, in-line degasser (G1379 A), binary pump (G1311 A), refrigerated autosampler (G1329 A/G1330B), and temperature-controlled column oven (G1316 A). Selected mass transitions and their respective collision energies (CE) are given in Table 1. Collision induced dissociation (CID) spectra were recorded in the Enhanced Product Ion (EPI) mode in the mass range from $\mathrm{m} / z 150$ to 1000 of $\mathrm{m} / \mathrm{z}$ $870, m / z 874$ and $m / z 904$. Positive ionization and unit resolution mode were used. The following parameters were applied: curtain gas: $10 \mathrm{psi}$, CAD: medium, ion spray voltage: $5500 \mathrm{~V}$, temperature: ambient, nebulizer gas: $10 \mathrm{psi}$, auxiliary gas: off, interface heater: on, declustering potential: $100 \mathrm{~V}$, collision energy spread: $0,10 \mathrm{~V}$, collision energy: $70 \mathrm{~V}$. For quantification the mass transitions $[\mathrm{M}+\mathrm{H}]^{+} \rightarrow[\mathrm{M}+\mathrm{H}-$ $\mathrm{H}_{2} \mathrm{O}{ }^{+}$were used. AZA were calibrated against an external calibration curve of AZA-1 standard solutions and results were expressed as AZA-1 equivalents.

\subsection{HRMS measurements}

LC-HRMS analysis was performed with a UHPLC system coupled to a hybrid quadrupole mass spectrometer (Vanquish UHPLC, Q Exactive Plus HRMS, both Thermo Fisher Scientific, Schwerte, Germany), using a heated electrospray ionization source. Separation was performed on a C18 column (C18 BEH, $100 \times 2 \mathrm{~mm}, 1,7 \mu \mathrm{m}$ particle size, ACQUITY Waters, equipped with guard-column) at a flowrate of $0.55 \mathrm{~mL} \mathrm{~min} \mathrm{~m}^{-1}$ (solvent $\mathrm{A}: \mathrm{H}_{2} \mathrm{O}+10 \mathrm{mM}$ ammonium formate (AF) and $0.1 \%$ formic
Table 1

Selected reaction monitoring (SRM) transitions monitored for AZAs in Azadinium culture extracts.

\begin{tabular}{|c|c|}
\hline Toxin & Mass transitions (Collision energy [V]) \\
\hline AZA-1 & $842>824(40), 842>672(70)$ \\
\hline Me-AZA-1 & $856>838(40), 856>672(70)$ \\
\hline AZA-2 & $856>838(40), 856>672(70)$ \\
\hline Me-AZA-2 & $870>852(40)$ \\
\hline AZA-2 phosphate & $936>918(40)$ \\
\hline AZA-3 & $828>810(40), 828>658(70)$ \\
\hline AZA-4 & $844>826(40)$ \\
\hline AZA-5 & $844>826(40)$ \\
\hline AZA-7 & $858>840(40)$ \\
\hline AZA-8 & $858>840(40)$ \\
\hline AZA-9 & $858>840(40)$ \\
\hline AZA-10 & $858>840(40)$ \\
\hline AZA-11 & $872>854(40)$ \\
\hline AZA-11 phosphate & $952>818(40)$ \\
\hline AZA-12 & $872>854(40)$ \\
\hline AZA-33 & $716>698(40)$ \\
\hline AZA-34 & $816>798(40)$ \\
\hline AZA-35 & $830>812(40)$ \\
\hline AZA-36 & $858>840(40), 858>348(70)$ \\
\hline AZA-37 & $846>828(40), 846>348(70)$ \\
\hline AZA-38 & $830>812(40), 846>348(70)$ \\
\hline AZA-39 & $816>798(40), 816>348(70)$ \\
\hline AZA-40 & $842>824(40), 842>348(70)$ \\
\hline AZA-41 & $854>836(40), 854>670(70), 854>360(70)$ \\
\hline AZA-42 & $870>852(40), 870>360(70)$ \\
\hline AZA-43 & $828>658(40)$ \\
\hline AZA-54 & $870>852(40)$ \\
\hline AZA-55 & $868>850(40)$ \\
\hline AZA-56 & $844>826(40)$ \\
\hline AZA-57 & $884>866(40)$ \\
\hline AZA-58 & $828>658(40)$ \\
\hline AZA-59 & $860>842(40)$ \\
\hline AZA-59 phosphate & $940>842(40)$ \\
\hline AZA-62 & $870>852(40)$ \\
\hline
\end{tabular}

acid (FA), solvent $\mathrm{B}$ : acetonitrile (ACN) $+10 \mathrm{mM} \mathrm{AF}$ and $0.1 \% \mathrm{FA}$ ). After injection, the samples were eluted isocratically at $10 \% \mathrm{~B}$ for $0.1 \mathrm{~min}$, followed by a $2.9 \mathrm{~min}$ gradient to $100 \% \mathrm{~B}$ and held for $1 \mathrm{~min}$. The re-equilibration phase at $10 \% \mathrm{~B}$ was $1 \mathrm{~min}$. To limit the 
accumulation of salt deposits, the first $0.6 \mathrm{~min}$ of each run were discarded to waste. The column oven was set to $32^{\circ} \mathrm{C}$. Full MS spectra (scan range of $m / z 500$ to 1500 ) were acquired with a resolution (RES) of 280,000 . Samples were then re-analysed using a range of dd-MS ${ }^{2}$ experiments (all scan range of $m / z 61$ to 905): 1) Data dependent fragmentation (full scan at RES $=70,000$ followed by dd-MS ${ }^{2}$ at NCE of 30 , automatic gain control (AGC) of $2 \mathrm{e} 5$, isolation window (IW) of 1.0 $m / z$, injection time (IT) of $50 \mathrm{~ms}$ and a RES $=17,500$ FWHM with an inclusion list of accurate masses $(\mathrm{m} / \mathrm{z}$ 872.5154, 870.4998, 868.53928, 856.52055 and 846.4423)); 2) data independent acquisition (DIA, inclusion list as above, $\mathrm{RES}=35,000, \quad \mathrm{IT}=50 \mathrm{~ms}, \quad \mathrm{AGC}=2 \mathrm{e}$, $\mathrm{IW}=1.0 \mathrm{~m} / z, \mathrm{NCE}=30$ ) and mixed full scan (RES 280,000, as above) and DIA (as above) in the same run. All experiments successfully detected the analytes with $>3$ point per peak. Assignments for the molecular formulas of the $[\mathrm{M}+\mathrm{H}]^{+}$ions were accepted when the mass tolerance was within the range of the instrument's error $(<1 \mathrm{ppm})$, data from the DIA experiment are shown. For all experiments, the transfer capillary temperature was set to $266^{\circ} \mathrm{C}$, the auxiliary gas heater to $400{ }^{\circ} \mathrm{C}$, the spray voltage was $3.5 \mathrm{kV}$, the sheath gas flow rate was 51 and auxiliary gas rate 13. Positive Ion Calibration Solution (Pierce, Thermo Fisher, Germany) was used for the calibration of the instrument.

\section{Results}

\subsection{AZA of planktonic origin}

To date, 24 AZA of algal origin have been described in the literature and two novel AZA are presented in this work (Table 2). The smallest known AZA is AZA-33 produced by Azadinium spinosum in the North Sea with a molecular mass of $715 \mathrm{Da}$ and the largest is AZA-56 produced by Azadinium dexteroporum in the Mediterranean Sea with a molecular mass of $885 \mathrm{Da}$. Thus, all known AZA comprise a molecular mass range of $170 \mathrm{Da}$. In addition to the AZA listed in Table 2, recently it was shown that AZA producing species are also capable of producing phosphorylated forms of AZA (Tillmann et al., 2016, 2017b). These AZA phosphates were not included in the AZA numbering, but are referred to as phosphates of the respective parent compounds. AZA phosphates display $80 \mathrm{Da}$ higher $\mathrm{m} / \mathrm{z}$ values than their parent compounds, but otherwise have almost identical CID spectra.

\section{2. $A Z A-42$}

The toxin profiles of strains AZFC25 and AZFC26 consisted of AZA$36\left(0.25\right.$ and $0.0027 \mathrm{fg} \mathrm{cell}^{-1}$, respectively), AZA-40 (4.38 and $0.031 \mathrm{fg}$ cell $\left.^{-1}\right)$, AZA-41 (0.34 and $\left.0.13 \mathrm{fg}^{\text {cell }}{ }^{-1}\right)$ all expressed as AZA-1 equivalents and a yet unknown compound (AZA-42) at $11.48 \mathrm{~min}$ with a $m / z$ of 870 . This mass is the same nominal mass as of AZA-2 methyl ester (Me-AZA-2), which had been included in the method as methylation of AZA can occur in methanolic solutions (Krock et al., 2012). Methylated AZA have later retention times in reversed phase chromatography as their respective non-methylated forms, but AZA-42 eluted more than one minute earlier than AZA-2, which prompted us to investigate the mass spectrometric characteristics of this compound. The CID spectrum of AZA-42 revealed the presence of the typical AZA group 1-5 fragments (Figs. 2A and 3 , Table 3), with a downshift of 2 Da in comparison to AZA-1 and an analogous fragmentation pattern to AZA41 (Krock et al., 2014). AZA-42 was a minor compound in both strains with cell quotas determined as $0.12 \mathrm{fg}^{\text {cell }}{ }^{-1}$ in strain AZFC25 and $0.05 \mathrm{fg}$ cell $^{-1}$ in strain AZFC26.

\subsection{AZA-62}

AZA-62 is a minor compound detected at 11.08 min with a $\mathrm{m} / \mathrm{z}$ of 870 in Southeast Pacific strains of $A$. poporum that have previously been described as producers of AZA-11 and its phosphate (Tillmann et al.,

Table 2

AZA, mass-to-charge $(\mathrm{m} / \mathrm{z})$ ratios of their pseudomolecular ions, $\mathrm{m} / \mathrm{z}$ values of characteristic group 4 and group 5 fragments (for explanation of the fragment groups see Fig. 3), producing species and references of reported AZA variants of planktonic origin. The missing AZA numbers in this list are shellfish metabolites, extraction artefacts or hypothesized variants that were not included in this summary but are reported elsewhere (Rehmann et al., 2008; Kilcoyne et al., 2018).

\begin{tabular}{|c|c|c|c|c|c|c|}
\hline$\#$ & AZA & $m / z[\mathrm{M}+\mathrm{H}]^{+}$ & $m / z$ group 4 fragment & $m / z$ group 5 fragment & Producer & Reference \\
\hline 1 & AZA-1 & 842 & 362 & 262 & Az. spinosum & Krock et al., 2009 \\
\hline \multirow[t]{3}{*}{2} & AZA-2 & 856 & 362 & 262 & Az. spinosum & Krock et al., 2009 \\
\hline & & & & & Az. poporum & Krock et al., 2014 \\
\hline & & & & & Am. languida & Tillmann et al., 2017a \\
\hline 3 & epi-AZA-7 & 858 & 362 & 262 & Az. dexteroporum & Rossi et al., 2017 \\
\hline \multirow[t]{2}{*}{4} & AZA-11 & 872 & 362 & 262 & Az. spinosum & Tillmann et al., 2018 \\
\hline & & & & & Az. poporum & Krock et al., 2014 \\
\hline 5 & AZA-33 & 716 & 362 & 262 & Az. spinosum & Kilcoyne et al., 2014 \\
\hline 6 & AZA-34 & 816 & 362 & 262 & Az. spinosum & Kilcoyne et al., 2014 \\
\hline \multirow[t]{2}{*}{7} & AZA-35 & 830 & 362 & 262 & Az. spinosum & Kilcoyne et al., 2014 \\
\hline & & & & & Az. dexteroporum & Rossi et al., 2017 \\
\hline 8 & AZA-36 & 858 & 348 & 248 & Az. poporum & Krock et al., 2015 \\
\hline 9 & AZA-37 & 846 & 348 & 248 & Az. poporum & Krock et al., 2015 \\
\hline 10 & AZA-38 & 830 & 348 & 248 & Am. languida & Krock et al., 2012 \\
\hline 11 & AZA-39 & 816 & 348 & 248 & Am. languida & Krock et al., 2012 \\
\hline 12 & AZA-40 & 842 & 348 & 248 & Az. poporum & Krock et al., 2014 \\
\hline 13 & AZA-41 & 854 & 360 & 260 & Az. poporum & Krock et al., 2014 \\
\hline 14 & AZA-42 & 870 & 360 & 260 & Az. poporum & This work \\
\hline 15 & AZA-43 & 828 & 360 & 260 & Am. languida & Tillmann et al., 2017a \\
\hline 16 & AZA-50 & 842 & 348 & 262 & Az. spinosum & Tillmann et al., 2018 \\
\hline 17 & AZA-51 & 858 & 348 & 262 & Az. spinosum & Tillmann et al., 2018 \\
\hline 18 & AZA-52 & 830 & 348 & 248 & Am. languida & Tillmann et al., 2018 \\
\hline 19 & AZA-53 & 830 & 348 & 248 & Am. languida & Tillmann et al., 2018 \\
\hline 20 & AZA-54 & 870 & 362 & 262 & Az. dexteroporum & Rossi et al., 2017 \\
\hline 21 & AZA-55 & 868 & 360 & 260 & Az. dexteroporum & Rossi et al., 2017 \\
\hline 22 & AZA-56 & 884 & 362 & 262 & Az. dexteroporum & Rossi et al., 2017 \\
\hline 23 & AZA-57 & 844 & 362 & 262 & Az. dexteroporum & Rossi et al., 2017 \\
\hline 24 & AZA-58 & 828 & 362 & 262 & Az. dexteroporum & Rossi et al., 2017 \\
\hline 25 & AZA-59 & 860 & 362 & 262 & Az. poporum & Kim et al., 2017 \\
\hline 26 & AZA-62 & 870 & 362 & 262 & Az. poporum & This work \\
\hline
\end{tabular}



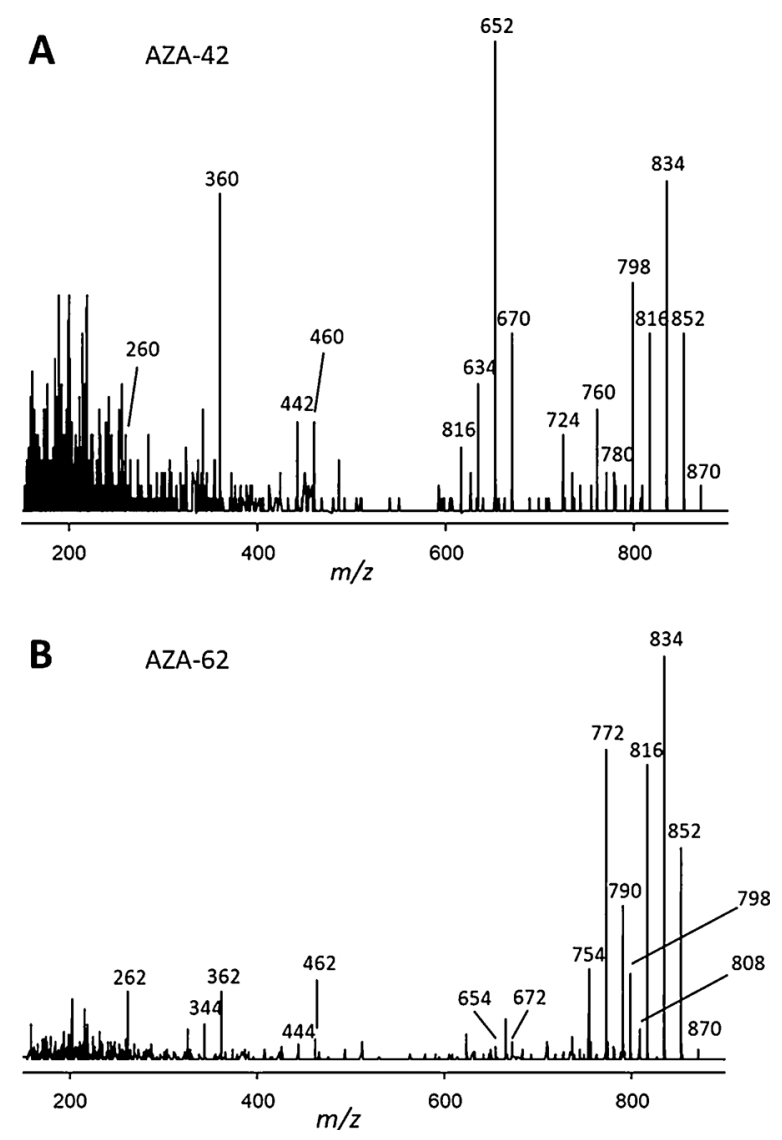

Fig. 2. Collision induced dissociation (CID) spectra of A) AZA-42 and B) AZA62 recorded on the triple quadrupole instrument.

2017b). During a thorough analysis of one of these strains with higher biomass, AZA-62 was detected in addition to AZA-11 and AZA-11 phosphate. In strain 1D5 the cell quota of AZA-62 was determined as $0.34 \mathrm{fg}_{\text {cell }^{-1}}$, which is $0,5 \%$ of AZA-11, both expressed as AZA-1 equivalents. The CID spectrum of AZA-62 also showed the typical group 1-5 fragments (Fig. 2B) with a CID spectrum identical to that of AZA-11 except for the 2 Da downshift of the group 1 fragments. An important difference between the spectra of AZA-11 and AZA-62 is the very low intensity of the group 2 fragments $m / z 654$ and 672 of AZA-62 (Fig. 2B)
Table 3

AZA-42 observed mass-to-charge $(\mathrm{m} / \mathrm{z})$ ratios of recorded fragments (for explanation of fragment groups see Fig. 3), elemental composition, and deviation from the calculated mass in ppm.

\begin{tabular}{llll}
\hline Ion & $m / z$ observed & Composition & \pm ppm \\
\hline$[\mathrm{M}+\mathrm{H}]^{+}$ & 870.4997 & $\mathrm{C}_{48} \mathrm{H}_{72} \mathrm{NO}_{13}$ & 0.78 \\
{$\left[\mathrm{M}+\mathrm{H}-\mathrm{H}_{2} \mathrm{O}\right]^{+}$} & 852.4889 & $\mathrm{C}_{48} \mathrm{H}_{70} \mathrm{NO}_{12}$ & 0.33 \\
{$\left[\mathrm{M}+\mathrm{H}-2 \mathrm{H}_{2} \mathrm{O}\right]^{+}$} & 834.4782 & $\mathrm{C}_{48} \mathrm{H}_{68} \mathrm{NO}_{11}$ & -0.60 \\
{$\left[\mathrm{M}+\mathrm{H}-\mathrm{CO}_{2}\right]^{+}$} & $\mathrm{n} / \mathrm{d}$ & & \\
Group-2 & 670.3945 & $\mathrm{C}_{38} \mathrm{H}_{56} \mathrm{NO}_{9}$ & -0.70 \\
Group-2 $-\mathrm{H}_{2} \mathrm{O}$ & 652.3845 & $\mathrm{C}_{38} \mathrm{H}_{54} \mathrm{NO}_{8}$ & 0.11 \\
Group-3 & 460.3059 & $\mathrm{C}_{27} \mathrm{H}_{42} \mathrm{NO}_{5}$ & 0.5 \\
Group-4 & 360.2535 & $\mathrm{C}_{22} \mathrm{H}_{34} \mathrm{NO}_{3}$ & 0.39 \\
Group-5 & $\mathrm{n} / \mathrm{d}$ & $\mathrm{C}_{10} \mathrm{H}_{16} \mathrm{NO}$ & -0.06 \\
Group-6 & 166.1226 & & \\
\hline
\end{tabular}

compared to AZA-11, where $m / z 654$ is the base peak of the entire spectrum.

\section{Discussion}

\subsection{AZA of dinoflagellate origin}

Currently there are four known AZA producers (Table 2): $A z$. poporum (AZA-2, -11, -36, -37, -40, -41, -42, -59 and -62), Az. spinosum (AZA-1, -2, -11, 33, -34, -35, -50 and -51), Az. dexteroporum (epi-AZA-7, AZA-35, 54, -55, -56, -57 and -58) and Am. languida (AZA-2, -38, -39, $-43,-52$ and -53 ). The highest number of AZA variants has been identified in strains of $A z$. poporum, and this probably reflects the high number of strains that have been obtained from various areas of the globe. Despite the low number and the limited geographic coverage of strains available for $A z$. dexteroporum, $A z$. spinosum and Am. languida, the AZA variability of these species (Az. spinosum: $8 \mathrm{AZA}, A z$. dexteroporum: 7 AZA, Am. languida: 6 AZA) is high as well (Table 2). Generally, with a low number and limited geographic coverage of strains it is difficult to evaluate species and/or regional specificity of AZA profiles. Some AZA are more widely distributed such as AZA-2, which occurs at least in some strains of all AZA-producers (Tillmann et al., 2009; Krock et al., 2014; Tillmann et al., 2017a) except for the only strain of toxigenic $A z$. dexteroporum available so far. AZA-35 has been reported from Az. spinosum (Kilcoyne et al., 2014) and from $A z$. dexteroporum (Rossi et al., 2017), and AZA-11 is known from at least some strains of both $A z$. spinosum (Tillmann et al., 2018) and Az. poporum (Tillmann et al., 2017b). The geographical distribution of different

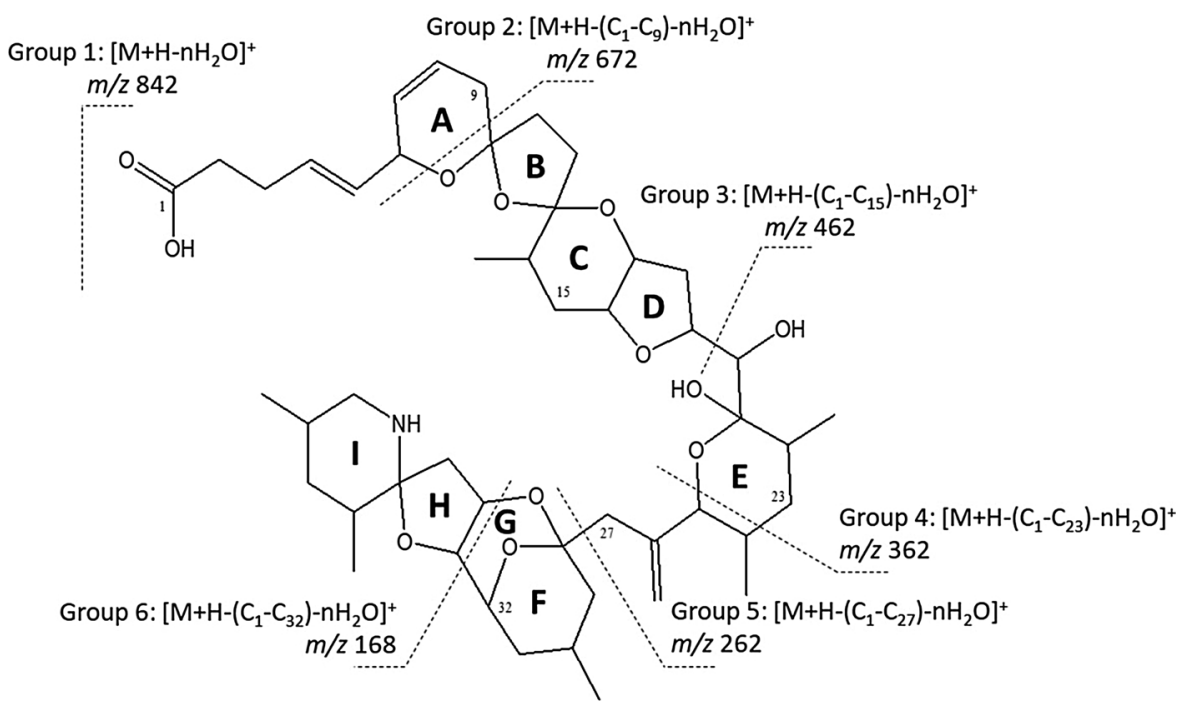

Fig. 3. Fragmentation scheme of AZA-1 indication the characteristic AZA fragment groups. 

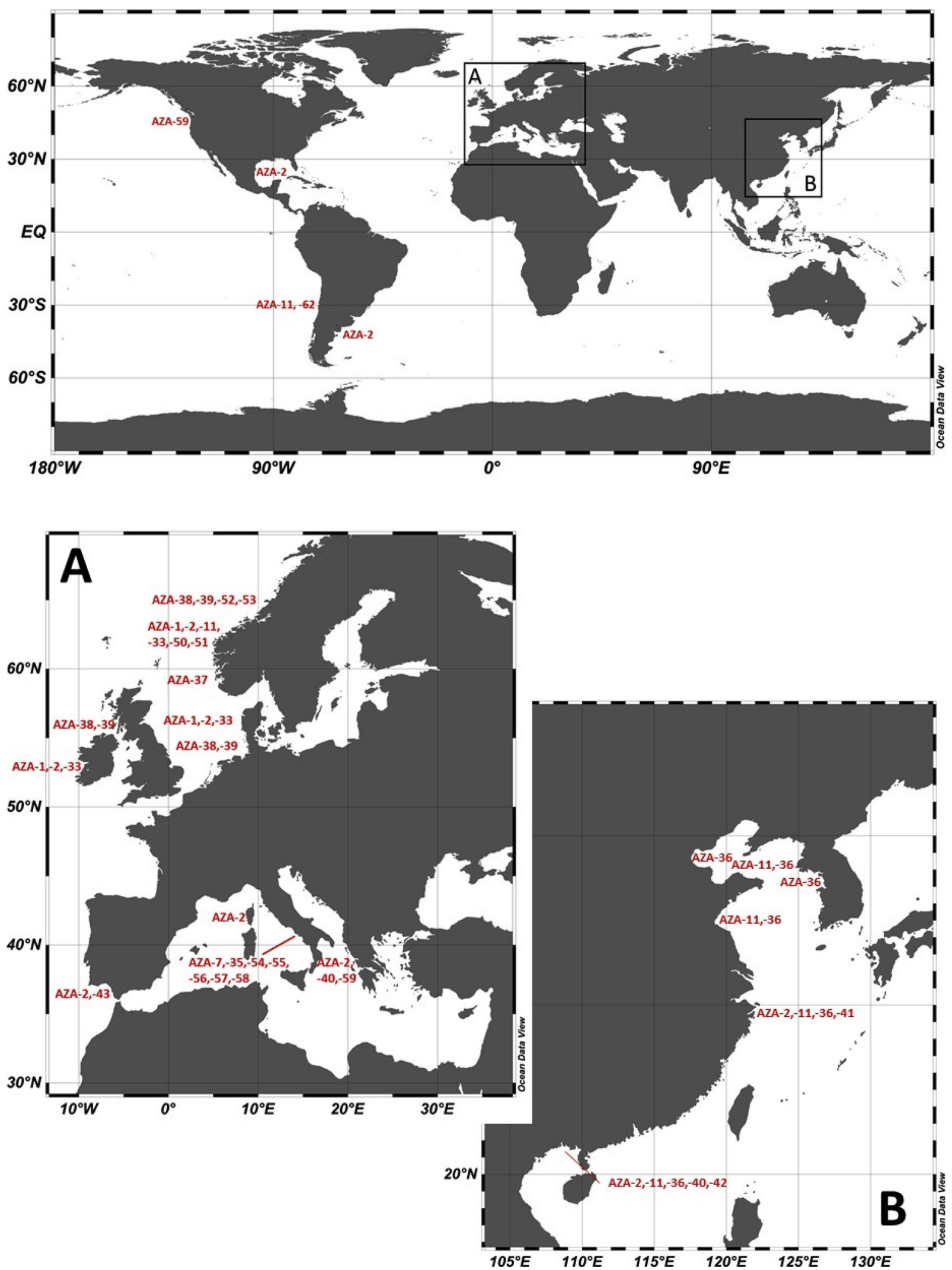

Fig. 4. Map showing the geographic origin of isolated AZA producers and their related AZA variants.

plankton AZA variants resembles areas where research on AZA producers has been performed, namely the Northeast Atlantic including the Mediterranean Sea, the Northwest Pacific and to a lesser extent the Southwest Atlantic and the Northeast and Southeast Pacific (Fig. 4).
Absence in other areas of the world ocean rather reflects the lack of related studies than the actual absence of AZA and their producers. The most widely distributed AZA analogue is AZA-2, which on one hand is produced by three different species and on the other is produced by $\mathrm{Az}$. 
Table 4

AZA-62 observed mass-to-charge $(\mathrm{m} / \mathrm{z}$ ) ratios of recorded fragments (for explanation of fragment groups see Fig. 3), elemental composition, and deviation from the calculated mass in ppm.

\begin{tabular}{llll}
\hline Ion & $m / z$ observed & Composition & \pm ppm \\
\hline$[\mathrm{M}+\mathrm{H}]^{+}$ & 870.4991 & $\mathrm{C}_{48} \mathrm{H}_{72} \mathrm{NO}_{13}$ & 0.85 \\
{$\left[\mathrm{M}+\mathrm{H}-\mathrm{H}_{2} \mathrm{O}\right]^{+}$} & 852.4889 & $\mathrm{C}_{48} \mathrm{H}_{70} \mathrm{NO}_{12}$ & 0.33 \\
{$\left[\mathrm{M}+\mathrm{H}-2 \mathrm{H}_{2} \mathrm{O}\right]^{+}$} & 834.4785 & $\mathrm{C}_{48} \mathrm{H}_{68} \mathrm{NO}_{11}$ & -0.28 \\
{$\left[\mathrm{M}+\mathrm{H}-\mathrm{CO}_{2}\right]^{+}$} & 790.4887 & $\mathrm{C}_{47} \mathrm{H}_{68} \mathrm{NO}_{9}$ & -0.26 \\
Group-2 & 672.4107 & $\mathrm{C}_{38} \mathrm{H}_{58} \mathrm{NO}_{9}$ & 0.15 \\
Group-3 & 462.3214 & $\mathrm{C}_{27} \mathrm{H}_{44} \mathrm{NO}_{5}$ & -0.10 \\
Group-4 & 362.2703 & $\mathrm{C}_{22} \mathrm{H}_{36} \mathrm{NO}_{3}$ & -0.06 \\
Group-5 & $\mathrm{n} / \mathrm{d}$ & $\mathrm{C}_{10} \mathrm{H}_{18} \mathrm{NO}$ & 0.29 \\
Group-6 & 168.1383 & & \\
\hline
\end{tabular}

poporum from very distant areas such as in Argentine coastal waters (Tillmann et al., 2016), the Gulf of Mexico (Luo et al., 2016), Chinese coastal waters (Krock et al., 2014), and the Mediterranean Sea (Luo et al., 2017). AZA-11 is another example for a widely distributed toxin which has been found both in the Pacific region (Tillmann et al., 2017b) as well as in the North Atlantic (Tillmann et al., 2018), and in the Mediterranean Sea (Luo et al., 2018). Other AZA, such as AZA-40 and AZA-59 were initially thought to be local phenomena, i.e. AZA-40 from the China Sea (Krock et al., 2014), and AZA-59 from coastal water of Washington State, USA (Kim et al., 2017), but recent data show that both of these compounds (albeit in very low amounts) also occur in the Eastern Mediterranean Sea (Luo et al., 2018). This clearly shows that 1) a wide geographical distribution may be a common feature for many, if not all AZA congeners and 2) that many unrecognized AZA derivatives pose a risk until inclusion in (targeted) screenings. This is likely to become more evident in the future when updated AZA analysis including the whole suite of newly detected compounds are increasingly applied for more field samples, strains and shellfish extracts.

A number of AZA currently are only described for a certain species (e.g., AZA-38, -39, -43, -52 and -52 by Am. languida, AZA-11, -36, -37, $-40,-41,-42,-59$ and -62 by $A z$. poporum, epi-AZA-7, AZA- 54 to -58 by Az. dexteroporum, and AZA-1, $-33,-34,-51,-52$ only by Az. spinosum). On the other hand, the very high AZA analogue variability that has been found so far for different strains of the same species and across geographically distinct areas, and the many areas where AZA profiles of the local species/population have not been determined yet, make it increasingly difficult and thus probably unlikely that AZA can reliably be used as chemotaxonomic markers at species or regional level. For example, it seems to be premature to take the presence of AZA-1 reported from shellfish tissue in China (Yao et al., 2010) and Chile (Álvarez et al., 2010; López-Rivera et al., 2010) as firm evidence for the presence of $A z$. spinosum. The former report likely is a misidentification as only single mass spectrometric analysis was used and isobaric AZA40 is occurring in the Northwest Pacific. The latter reports from Chile originate from two independent groups and are absolutely reliable. Despite the occurrence of AZA-1 in the Pacific, no AZA-1 producing strains from the Pacific are available yet and thus the question whether A. spinosum or other species of the Amphidomataceae are responsible for the occurrence of AZA-1 in the Pacific, remains open. As a conclusion, further research is needed to fully understand AZA variability across producing species and geographic regions.

Structurally, AZA are relatively conserved with most modifications being methylations or hydroxylations located at the biosynthetic end of the molecule, i.e. towards the carboxylic function (Kalaitzis et al., 2010). Nevertheless, there are also truncated forms of AZA with a reduced carbon number such as AZA-33, -34 and -35 (Kilcoyne et al., 2014). In contrast to this general observation, there are two modifications observed in AZA that occur at the opposite part of the molecule, namely the I-ring. Most AZA have a saturated I-ring and are methylated at the 39-position of the molecule, which results in a group 5 fragment $m / z 362$ (Table 2, Fig. 2). In some AZA, however, the I-ring is either unsaturated (resulting in a group 5 fragment of $m / z 360$ ) or demethylated at the 39-position (resulting in a group 5 fragment of $m / z 348$ ).

\section{2. $A Z A-42$}

Collision induced dissociation (CID) mass spectra of AZA-41 (Krock et al., 2014) and AZA-42 (Fig. 2A), both produced by Az. poporum strains isolated from the South China Sea, share identical group 2 to group 5 fragments indicating a high degree of structural similarity among both compounds. Only the pseudomolecular ion cluster of AZA42 is shifted to $16 \mathrm{Da}$ higher masses indicating an additional incorporation of one oxygen atom into AZA-42 in comparison to AZA-41. The supposed elemental composition of AZA- 42 was confirmed by high resolution mass spectrometry (HRMS) as the calculated sum formula of AZA-42 $\left(\mathrm{C}_{48} \mathrm{H}_{72} \mathrm{NO}_{13}\right)$ is identical with AZA-41 except for an additional oxygen (Table 3 ). This is also in line with the observation that the pseudomolecular ion of AZA-42 $(\mathrm{m} / \mathrm{z}$ 870) shows five water losses, whereas AZA-41 only shows four water losses (Table 3, Fig. 2A and Krock et al., 2014). These observations are strong evidence that AZA-42 is an hydroxylated form of AZA-41. Since all CID fragments below $m / z$ 670 are identical among both compounds and their elemental composition has been confirmed by HRMS (Table 3), the hydroxylation site must be located between C2 and C9, except for C3. C3 hydroxylated AZA consistently eliminate $\mathrm{CO}_{2}$ under CID conditions (Krock et al., 2015), which is not observed in the CID spectrum of AZA-42. Nevertheless, for full structural elucidation NMR spectroscopy will be needed, which is challenging for minor compounds like AZA-42, because biomass in the mid microgram range needs to be produced to provide sufficient AZA for isolation and purification.

\section{3. $A Z A-62$}

With a pseudomolecular mass of $m / z 870$ AZA-62 is isobaric with AZA-42 and even more, both compounds with the sum formula $\mathrm{C}_{48} \mathrm{H}_{72} \mathrm{NO}_{13}$ share the identical elemental composition (Tables 3 and 4) and cannot be differentiated by HRMS alone. Despite of this identity both compounds show very distinct CID spectra, which clearly indicates different structural elements among AZA-42 and AZA-62. Even though both AZA are of Az. poporum origin, AZA-62, in contrast to AZA-42 from the South China Sea, is produced by a strain isolated at the North Chilean coast. The main AZA produced by the Chilean Az. poporum strain is AZA-11 and not surprisingly the CID spectra of AZA-11 (Tillmann et al., 2017b) and AZA-62 (Fig. 2B) share common features. First of all, group 3 to group 5 fragments of both AZA are identical, which indicates a conserved structure in the C24-C40 region. Furthermore, the pseudomolecular ion of AZA-62 is $2 \mathrm{Da}$ lower than of AZA-11. Another common feature is the loss of $\mathrm{CO}_{2}$, which is typical for 3-hydroxylated AZA such as AZA-11. Comparing the elemental composition of both compounds revealed by HRMS in fact reveals that AZA62 has two hydrogen atoms less than AZA-11 indicating an unsaturation in AZA-62. The most obvious difference between the CID spectra of AZA-62 and AZA-11 is the lack of the group 2 fragments in AZA-62. Group 2 fragments of AZA are formed by a Retro-Diels-Alder (RDA) reaction of the A-ring, which apparently does not occur in AZA-62. This indicates that the unsaturation must be located in close proximity to the A-ring in order to be able to change the electronic configuration and thus the stability of the chemical bonds in this part of the molecule. Since there are no characteristic fragments of AZA-62 in the mass range between group 3 fragment $m / z 462$ and the pseudomolecular ion $m / z$ 870 , the location of the additional double bond cannot be attributed more specifically than between $\mathrm{C} 1-\mathrm{C} 23$. In order to be able to suppress the RDA reaction, it is reasonable to assume that this double bond is located at $\mathrm{C} 11 / \mathrm{C} 12$. But this is only indirect evidence that certainly needs to be confirmed by NMR spectroscopy.

Quantitation of AZA by LC-MS/MS generally is a problem as 
calibration standards are available only for very few variants (mainly AZA-1, -2 and -3), which implies that all other AZA variants cannot be quantified in an analytically strict sense, because the molecular response in LC-MS/MS among AZA variants may be variable. Most methods use the mass transition of the pseudo-molecular $[\mathrm{M}+\mathrm{H}]^{+}$ion to the first water loss $\left[\mathrm{M}+\mathrm{H}-\mathrm{H}_{2} \mathrm{O}\right]^{+}$for quantitation. If CID spectra of AZA are compared, it becomes evident that the intensities of the first water loss across all AZA are similar (e.g. Fig. 2) and a molecular response at least in the same order of magnitude can be assumed. For this reason, quantitation of AZA variants without quantitation standards by calibration using a standard of a different AZA such as AZA-1 and expression as AZA-1 equivalent, for example, is an excellent tool for relative quantitation (e.g. in comparison of different treatments). Even though in terms of absolute quantitation AZA equivalents may not result in an analytically precise value, but still give a good estimate of a certain quantity of an AZA without available standard.

The novel AZA variants reported here are minor constituents of the respective AZA profiles and - notwithstanding that their relative toxicities are not known - probably will not be main contributors to overall toxicity of the producing strains. Despite their relatively little contribution to the AZA profiles, such minor compounds are interesting from a research perspective for several reasons:

1) Increased knowledge of structural variants of a given toxin class yields a better understanding of the involved biosynthetic pathways. It is believed that AZA are biosynthesized by polyketide synthases through chain elongation of an initial amino acid resulting in the amino ring. Except for two modifications of the amino or I-ring of AZA, namely an unsaturation or demethylation, the initial part of AZA remains conserved in almost all known AZA, whereas other biosynthetic modifications start towards the biosynthetic end of AZA including truncation of the carbon chain. This may be an indication that structural variability at the biosynthetic end of the molecules does not severely affect their ecological function.

2) Additionally, rare AZA variants can serve as geographic markers for a producing species. Nevertheless, it is not known, if observed patterns of AZA variability are a result of evolutionary processes or of spreading of species and genotypes.. The improvement of analytic tools and availability of in-depth toxin databases enables the detection of AZA producers in areas via AZA as their chemotaxonomic markers in remote areas where species identification by microscopic and/or genetic tools is not possible.

3) With more CID spectra of AZA available, structural information can be more easily deduced from new CID spectra through analogies and specific differences of the spectra. This is particularly useful as AZA are often produced at a $\mathrm{fg} \mathrm{cell}^{-1}$ scale and collection of sufficient biomass for full structural elucidation by nuclear magnetic resonance spectrometry may be challenging or virtually impossible in some cases.

4) Knowledge of all AZA in seafood samples enables a more accurate estimation of overall toxicity and risk for human health.

\section{Conclusions}

Until the discovery of the AZA producing species, AZA variants were isolated from shellfish and described as products of either AZA-1 or AZA-2. Since Az. spinosum was identified as the first AZA producer in 2007, 26 novel AZA variants from dinoflagellate origin have been described. None of these novel AZA are regulated and virtually nothing is known on their metabolic products formed in mollusks. This highlights the need for not only monitoring regulated AZA, but also to include locally relevant variants, to investigate shellfish metabolites of AZA other than AZA-1/2 and to perform toxicity testing of these novel variants.

Furthermore, the actual structural diversity of AZAs is likely much higher and there are likely yet unknown AZA producing species, therefore, the current state of knowledge on the global ecological importance and threat of AZA and their producers is still limited.

\section{Conflict of interests}

There no conflicts of interest in the content of this work.

\section{Acknowledgements}

This work was partially funded by the Helmholtz-Gemeinschaft Deutscher Forschungszentren through the research program PACES II of the Alfred Wegener Institut-Helmholtz Zentrum für Polar- und Meeresforschung, the binational project CONICYT-BMBF (CONICYT Grant \# 2011-504/BMBF Grant \# CHL 11/011 (01DN12102)) and the BMBF project "RIPAZA" (grant no. 03F0763A). [CG]

\section{References}

Álvarez, G., Uribe, E. Ávalos, P., Mariño, C., Blanco, J., 2010. First identification of azaspiracid and spirolides in Mesodesma donacium and Mulinia edulis from Northern Chile. Toxicon 55 (2-3), 638-641.

James, K.J., Sierra, M.D., Lehane, M., Braña Magdalena, A., Furey, A., 2003. Detection of five new hydroxyl analogues of azaspiracids in shellfish using multiple tandem mass spectrometry. Toxicon 41 (3), 277-283.

Kalaitzis, J.A., Chau, R., Kohli, G.S., Murray, S.A., Neilan, B.A., 2010. Biosynthesis of toxic naturally-occurring seafood contaminants. Toxicon 56 (2), 244-258.

Kilcoyne, J., Keogh, A., Clancy, G., LeBlanc, P., Burton, I.W., Quilliam, M.A., Hess, P., Miles, C.O., 2012. Improved Isolation Procedure for Azaspiracids from Shellfish, Structural Elucidation of Azaspiracid-6, and Stability Studies. J. Agric. Food Chem. 60 (10), 2447-2455.

Kilcoyne, J., Nulty, C., Jauffrais, T., McCarron, P., Herve, F., Foley, B., Rise, F., Crain, S., Wilkins, A.L., Twiner, M.J., Hess, P., Miles, C.O., 2014. Isolation, Structure Elucidation, Relative LC-MS Response, and in Vitro Toxicity of Azaspiracids from the DinoflagellateAzadinium spinosum. J. Nat. Prod. 77 (11), 2465-2474.

Kilcoyne, J., McCarron, P., Twiner, M.J., Rise, F., Hess, P., Wilkins, A.L., Miles, C.O., 2018. Identification of 21,22-Dehydroazaspiracids in Mussels (Mytilus edulis) and in Vitro Toxicity of Azaspiracid-26. J. Nat. Prod. 81 (4), 885-893.

Kim, J.-H., Tillmann, U., Adams, N.G., Krock, B., Stutts, W.L., Deeds, J.R., Han, M.-S., Trainer, V.L., 2017. Identification of Azadinium species and a new azaspiracid from Azadinium poporum in Puget Sound, Washington State, USA. Harmful Algae 68 (Supplement C), 152-167.

Krock, B., Tillmann, U., John, U., Cembella, A.D., 2009. Characterization of azaspiracids in plankton size-fractions and isolation of an azaspiracid-producing dinoflagellate from the North Sea. Harmful Algae 8 (2), 254-263.

Krock, B., Tillmann, U., Voß, D., Koch, B.P., Salas, R., Witt, M., Potvin, É., Jeong, H.-J., 2012. New azaspiracids in Amphidomataceae (Dinophyceae). Toxicon 60 (5), $830-839$.

Krock, B., Tillmann, U., Witt, M., Gu, H., 2014. Azaspiracid variability of Azadinium poporum (Dinophyceae) from the China Sea. Harmful Algae 36, 22-28.

Krock, B., Tillmann, U., Potvin, É., Jeong, H.-J., Drebing, W., Kilcoyne, J., Al-Jorani, A., Twiner, M., Göthel, Q., Köck, M., 2015. Structure Elucidation and in Vitro Toxicity of New Azaspiracids Isolated from the Marine DinoflagellateAzadinium poporum. Mar. Drugs 13 (11), 6687-6702.

López-Rivera, A., O'Callaghan, K., Moriarty, M., O’Driscoll, D., Hamilton, B., Lehane, M. James, K.J., Furey, A., 2010. First evidence of azaspiracids (AZAs): A family of lipophilic polyether marine toxins in scallops (Argopecten purpuratus) and mussels (Mytilus chilensis) collected in two regions of Chile. Toxicon 55 (4), 692-701.

Luo, Z., Krock, B., Mertens, K.N., Price, A.M., Turner, R.E., Rabalais, N.N., Gu, H., 2016. Morphology, molecular phylogeny and azaspiracid profile of Azadinium poporum (Dinophyceae) from the Gulf of Mexico. Harmful Algae 55, 56-65.

Luo, Z., Krock, B., Mertens, K.N., Nézan, E., Chomérat, N., Bilien, G., Tillmann, U., Gu, H., 2017. Adding new pieces to the Azadinium (Dinophyceae) diversity and biogeography puzzle: Non-toxigenicAzadinium zhuanum sp. nov. from China, toxigenic A. poporum from the Mediterranean, and a non-toxigenic A. dalianense from the French Atlantic. Harmful Algae 66, 65-78.

Luo, Z., Krock, B., Giannakourou, A., Venetsanopoulou, A., Pagou, K., Tillmann, U., Gu, H., 2018. Sympatric occurrence of two Azadinium poporum ribotypes in the Eastern Mediterranean Sea. Harmful Algae 78, 75-85.

McMahon, T., Silke, J., 1996. West coast of Ireland; winter toxicity of unknown aetiology in mussels. Harmful Algae News 14 (1), 2.

Ofuji, K., Satake, M., McMahon, T., Silke, J., James, K.J., Naoki, H., Oshima, Y., Yasumoto, T., 1999. Two Analogs of Azaspiracid Isolated from Mussels,Mytilus edulis, Involved in Human Intoxication in Ireland. Nat. Toxins 7 (3), 99-102.

Ofuji, K., Satake, M., McMahon, T., James, K.J., Naoki, H., Oshima, Y., Yasumoto, T., 2001. Structures of azaspiracid analogs, azaspiracid-4 and azaspiracid-5, causative toxins of azaspiracid poisoning in Europe. Biosci. Biotechnol. Biochem. 65 (3), 740-742.

Percopo, I., Siano, R., Rossi, R., Soprano, V., Sarno, D., Zingone, A., 2013. A new potentially toxic Azadiniumspecies (Dinophyceae) from the Mediterranean Sea,A. dexteroporum sp. nov. J. Phycol. 49 (5), 950-966. 
Rehmann, N., Hess, P., Quilliam, M.A., 2008. Discovery of new analogs of the marine biotoxin azaspiracid in blue mussels Mytilus edulis by ultra-performance liquid chromatography/tandem mass spectrometry. Rapid Commun. Mass Spectrom. 22 (4), 549-558.

Rossi, R., Dell'Aversano, C., Krock, B., Ciminiello, P., Percopo, I., Tillmann, U., Soprano, V., Zingone, A., 2017. Mediterranean Azadinium dexteroporum (Dinophyceae) produces six novel azaspiracids and azaspiracid-35: a structural study by a multi-platform mass spectrometry approach. Anal. Bioanal. Chem. 409 (4), 1121-1134.

Satake, M., Ofuji, K., Naoki, H., James, K.J., Furey, A., McMahon, T., Silke, J., Yasumoto, T., 1998. Azaspiracid, a New Marine Toxin Having Unique Spiro Ring Assemblies, Isolated from Irish Mussels,Mytilus edulis. J. Am. Chem. Soc. 120 (38), 9967-9968.

Tillmann, U., Elbrächter, M., Krock, B., John, U., Cembella, A.D., 2009. Azadinium spinosumgen. et sp nov (Dinophyceae) identified as a primary producer of azaspiracid toxins. Eur. J. Phycol. 44 (1), 63-79.

Tillmann, U., Borel, C.M., Barrera, F., Lara, R., Krock, B., Almandoz, G.O., Witt, M., Trefault, N., 2016. Azadinium poporum from the Argentine Continental Shelf,
Southwestern Atlantic, produces azaspiracid-2 and azaspiracid-2 phosphate. Harmful Algae 51, 40-55.

Tillmann, U., Jaén, D., Fernández, L., Gottschling, M., Witt, M., Blanco, J., Krock, B., 2017a. Amphidoma languida (Amphidomatacea, Dinophyceae) with a novel azaspiracid toxin profile identified as the cause of molluscan contamination at the Atlantic coast of southern Spain. Harmful Algae 62, 113-126.

Tillmann, U., Trefault, N., Krock, B., Parada-Pozo, G., De la Iglesia, R., Vásquez, M. 2017b. Identification of Azadinium poporum (Dinophyceae) in the Southeast Pacific: morphology, molecular phylogeny, and azaspiracid profile characterization. J. Plankton Res. 39 (2), 350-367.

Tillmann, U., Edvardsen, B., Krock, B., Smith, K.F., Paterson, R.F., Voß, D., 2018. Diversity, distribution, and azaspiracids of Amphidomataceae (Dinophyceae) along the Norwegian coast. Harmful Algae 80, 15-34.

Yao, J., Tan, Z., Zhou, D., Guo, M., Xing, L., Yang, S., 2010. Determination of azaspiracid1 in shellfish by liquid chromatography with tandem mass spectrometry. Chinese J. Chromatogr. 28 (4), 363-367. 